\title{
Active extracts of black tea (Camellia Sinensis) induce apoptosis of PC-3 prostate cancer cells via mitochondrial dysfunction
}

\author{
SHILI SUN, SHUNSHUN PAN, AIQING MIAO, CAIJIN LING, \\ SHI PANG, JINCHI TANG, DONG CHEN and CHAOYI ZHAO \\ Drink Plant Research Institute/Tea Research Center, Guangdong Academy of \\ Agricultural Sciences, Guangzhou, Guangdong 510640, P.R. China
}

Received March 27, 2013; Accepted May 7, 2013

DOI: $10.3892 /$ or.2013.2504

\begin{abstract}
Cancer of the prostate gland is the most common invasive malignancy and the second leading cause of cancerrelated death in human males. Many studies have shown that black tea reduces the risk of several types of cancer. We studied the effects of active extracts of black tea and the black tea polyphenols theaflavins (TFs), on the cellular proliferation and mitochondria of the human prostate cancer cell line PC-3. Our studies revealed that Yinghong black tea extracts (YBT), Assam black tea extracts (ABT) and TFs inhibited cell proliferation in a dose-dependent manner. We also showed that TFs, YBT and ABT affected the morphology of PC-3 cells and induced apoptosis or even necrosis in PC-3 cells. In addition, it was observed that the samples significantly caused loss of the mitochondrial membrane potential, release of cytochrome $c$ from the intermembrane space into the cytosol, decrease of the ATP content and activation of caspase-3 compared with the control. Taken together, these findings suggest that black tea could act as an effective anti-proliferative agent in PC-3 cells, and TFs, YBT and ABT induced apoptosis of PC-3 cells through mitochondrial dysfunction.
\end{abstract}

\section{Introduction}

Tea, one of the most widely consumed beverages in the world, has diverse pharmacological activities, including anti-hyperglycemia, antioxidative, anti-obesity and antitumor activities (1-4). Green tea, consumed at high levels in Asian countries, and black tea, consumed primarily in Western countries, are derived from leaves of Camellia sinensis (5).

Correspondence to: Professor Dong Chen or Professor Chaoyi Zhao, Drink Plant Research Institute/Tea Research Center, Guangdong Academy of Agricultural Sciences, Guangzhou, Guangdong 510640, P.R. China

E-mail: chendong1113@sohu.com

E-mail: zhaochaoyi_66@sina.com

Key words: theaflavins, black tea, PC-3 cells, mitochondria, cytochrome $c$
During the past decades, numerous in vitro and in vivo studies have showed the possible protective effects of tea and tea polyphenols on cancer and other diseases (6-8). Catechins are the most abundant polyphenol in green tea, whereas the typical pigments in black tea are formed from catechin oxidation during fermentation which includes theaflavins, thearubigins and theabrownins (9). Among them, the major theaflavins in black tea are theaflavin (TF1), theaflavin-3-gallate (TF2A), theaflavin-3'-gallate (TF2B) and theaflavin-3,3'-digallate (TF3) (Fig. 1). Therefore, the monomeric polyphenol content of black tea is low. However, it is not diminished for black tea during partial polymerization or other alterations in the fermentation of tea leaves (10), as it was proved that TF3 showed higher antioxidative activity than EGCG (11).

Apoptosis can occur via the mitochondria. The mitochondria is essential for energy production, and is involved in reactive oxygen species (ROS) generation and induction of apoptosis (12). In most tissues, the mitochondria accounts for the generation of $\sim 90 \%$ of the ATP needed by the cells (13). Mitochondrial dysfunction causes permeabilization of the outer mitochondrial membrane (14) and then leads to the release of the intermembrane space proteins such as cytochrome $c$, which ultimately triggers apoptotic cell death (15). Therefore, the mitochondrial permeability transition event could serve as an early indicator of the initiation of apoptosis. This mitochondrial permeability transition process results in the collapse of the electrochemical gradient across mitochondrial membrane and thus could be measured by noting the changes of the mitochondrial membrane potential (14).

Prostate cancer is one of the leading causes of human male deaths throughout the world (16). It is a group of cancerous cells (a malignant tumor) that grow mostly from the outer part of the prostate (17). In our previous study, we evaluated time- and dose-dependent cytotoxicity of EGCG and $\mathrm{Zn}^{2+}$ on PC-3 cells by the MTT assay (18). Whereas, in another study, we found that EGCG, $\mathrm{Zn}^{2+}$ and $\mathrm{EGCG}+\mathrm{Zn}^{2+}$ induced apoptosis or even necrosis of PC-3 cells through the mitochondria-mediated pathway, and free $\mathrm{Zn}^{2+}$ enhanced the effects of EGCG on PC-3 cells due to its interactions with mitochondria (19). In the present study, we investigated effects of black tea extracts on the viability and morphology of PC-3 cells, the functions of mitochondria of PC-3 cells, 
including mitochondrial membrane potential, cytochrome $c$ release, ATP contents and caspase-3 activities.

\section{Materials and methods}

Materials. Yinghong black tea (YBT) was obtained from Tea Research Institute, Guangdong Academy of Agricultural Sciences in China. Assam black tea (ABT) was purchased from Premier's Tea Limited in India. Theaflavins (TFs, $>50 \%$ purity) were obtained from Hangzhou Easily Biotechnology Co. Ltd (Hangzhou, China). HEPES and ATP were all purchased from Sigma (St. Louis, MO, USA). Mitochondrial membrane potential assay kit with JC-1 and caspase-3 activity assay kit were purchased from Beyotime Institute of Biotechnology (Shanghai, China). EdU solution was obtained from Guangzhou RiboBio Co. Ltd. (Guangzhou, China). The cell apoptosis Annexin V-FITC detection kit was purchased from Nanjing KeyGen Biotech. Co. Ltd. (Nanjing, China). Cytochrome $c \mathrm{pAb}$ was purchased from Bioworld Technology (Louis Park, MN, USA). Human prostate cancer cells (PC-3) were obtained from Shanghai Institute of Cell Biology, Chinese Academy of Sciences. All other chemicals were extra-pure grade or analytical grade except those explained in the study.

Preparation of black tea extracts and cell culture. Black tea was minced and extracted three times by placing in the boiling distilled water for $10 \mathrm{~min}$ each time (tea/water, $1: 5 \mathrm{w} / \mathrm{v}$ ). These extracted solutions were combined and concentrated at $60^{\circ} \mathrm{C}$ with RE-2000 Rotary Evaporator (Yarong Biochemical Instrument, Shanghai, China). Finally, the solution was dried by lyophilization (Savant Novalyphe-NL500, USA) to obtain the aqueous extract.

The contents of catechin and theaflavin monomers were analyzed using a high performance liquid chromatography (HPLC) system (Shimadzu LC-2010, Kyoto, Japan). The TFs, YBT and ABT extracts were analyzed on a Diamonsil C18 column (4.6x250 mm, $5 \mu \mathrm{m}$ particle size, Japan). The eluate was monitored at $280 \mathrm{~nm}$. Mobile phase A and B were made of acetic acid/acetonitrile/water (A: 0.5:3:96.5 and B: 0.5:30:69.5, by volume). The flow rate was set at $1 \mathrm{ml} / \mathrm{min}$ and $10 \mu 1$ sample was injected into the column. The elution was performed using a linear gradient from solvent A to solvent B in $45 \mathrm{~min}$ followed by an isocratic step of solvent B for $15 \mathrm{~min}$. The column temperature was set to $28^{\circ} \mathrm{C}$. Peaks were identified in comparison with the retention time of authentic standards.

PC- 3 cells were cultured in F-12 medium (Gibco, Invitrogen Corp., Carlsbad, CA, USA) supplemented with $10 \%$ fetal bovine serum (FBS) and $100 \mathrm{U} / \mathrm{ml}$ penicillin-streptomycin. The cells were cultured in a $5 \% \mathrm{CO}_{2}$ humidified atmosphere at $37^{\circ} \mathrm{C}$.

MTT and EdU assays. PC-3 cells were seeded on 96-well plates for $24 \mathrm{~h}$ and then incubated with $0.4,0.8,1.2,1.6$, $2.0 \mathrm{mg} / \mathrm{ml} \mathrm{TFs}$, YBT and ABT for 12, 24 and $36 \mathrm{~h}$, respectively. Thereafter, $20 \mu 1$ of $5 \mathrm{mg} / \mathrm{ml}$ MTT was added to each well from a stock solution and cultured for another 4 h. Finally, the reaction was stopped by addition of $150 \mu \mathrm{l}$ of dimethyl sulfoxide (DMSO). The absorbance in each well was measured with the microplate reader (Thermal Labsystem, Helsinki, Finland) at $490 \mathrm{~nm}$.

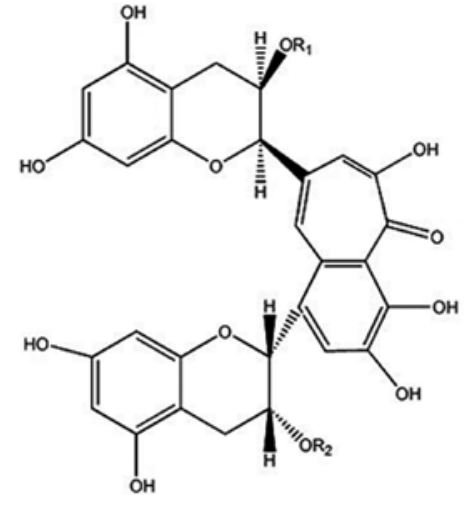

Figure 1. Chemical structures of theaflavins. TF1=Theaflavin $R_{1}=R_{2}=H$; TF2A=Theaflavin-3-gallate $\mathrm{R}_{1}=$ galloyl $\mathrm{R}_{2}=\mathrm{H}$; TF2B $=$ Theaflavin-3'-gallate $\mathrm{R}_{1}=\mathrm{H} \mathrm{R}_{2}=$ galloyl; TF3=Theaflavin-3,3'-digallate $\mathrm{R}_{1}=\mathrm{R}_{2}=$ galloyl.

The proliferation of PC-3 cells was estimated using the EdU incorporation assay. Briefly, the PC-3 cells $\left(1 \times 10^{5}\right)$ were exposed to $0.4 \mathrm{mg} / \mathrm{ml} \mathrm{YBT}$, ABT and TFs for $24 \mathrm{~h}$, respectively. The cells were cultured in 24 -well plates and exposed to $50 \mu \mathrm{mol} / 1 \mathrm{EdU}$ for $2 \mathrm{~h}$ at $37^{\circ} \mathrm{C}$. The cells were then fixed in $4 \%$ formaldehyde for $30 \mathrm{~min}$ at room temperature and permeabilized in $0.5 \%$ TritonX-100 for $10 \mathrm{~min}$. Cells were washed with PBS, and each well was incubated with $100 \mu 1 \mathrm{1X}$ Apollo ${ }^{\circledR}$ reaction cocktail for $30 \mathrm{~min}$. DNA was then stained with $100 \mu 1$ 1X Hoechst 33342 for $30 \mathrm{~min}$ and imaged under a fluorescent microscope.

Morphological changes of adhesive PC-3 cells. PC-3 cells were cultured in 6-wells plates $(20 \times 20 \mathrm{~mm})$ and then exposed to $0.4 \mathrm{mg} / \mathrm{ml} \mathrm{YBT}$, ABT and TFs for $24 \mathrm{~h}$. After exposure, the images of adhesive PC-3 cells were made through the inverted microscope at 10x10 magnifications (XDS-1B, Chongqing, China). The number of cells adhering on the plate and the changes of cell morphology indicated the cytotoxicity of YBT, $\mathrm{ABT}$ and TFs on PC-3 cells.

Apoptosis of PC-3 cells. The apoptosis of PC-3 cells was measured by flow cytometry. PC-3 cells were treated with $0.4 \mathrm{mg} / \mathrm{ml}$ YBT, ABT and TFs for $24 \mathrm{~h}$, and then cell apoptosis was analyzed by Annexin V-FITC apoptosis detection kit following the manufacturer's instructions. Briefly, PC-3 cells were gently trypsinized, washed twice with PBS, suspended in binding buffer $\left(1 \times 10^{6}\right.$ cells $\left./ \mathrm{ml}\right)$. Then, $0.5 \mathrm{ml}$ suspension with $1.25 \mu \mathrm{l}$ Annexin V-FITC and $10 \mu \mathrm{l}$ PI was incubated at room temperature in the dark for $15 \mathrm{~min}$, and analyzed immediately by flow cytometer (Becton Dickinson Immunocytometry System, San Jose, CA, USA).

Isolation and purification of mitochondria. The lowest effective concentration for suppressing PC-3 cells measured by the MTT assay was $0.4 \mathrm{mg} / \mathrm{ml}$ in our previous study (unpublished data). Therefore, in the present study, YBT, ABT and TFs were prepared at equal concentrations $(0.4 \mathrm{mg} / \mathrm{ml})$ to investigate the bioactivity of black tea. The PC-3 cells were seeded on $50-\mathrm{cm}^{2}$ plates at a density of $6 \times 10^{5}$ cells $/ \mathrm{ml}$ and allowed to grow for $24 \mathrm{~h}$. After treatment with $0.4 \mathrm{mg} / \mathrm{ml} \mathrm{YBT,} \mathrm{ABT} \mathrm{and} \mathrm{TFs}$ for $24 \mathrm{~h}$, the cells were harvested by centrifugation at 1,500 rpm for 5 min at $4^{\circ} \mathrm{C}$, and washed twice with cold PBS and 
finally re-suspended in the cold PBS. These cells were lysed by Ultrasonic Cell Disruption System (JY92-II, Chongqing, China) and centrifuged at $3,000 \mathrm{rpm}$ for $10 \mathrm{~min}$ at $4{ }^{\circ} \mathrm{C}$. The supernatant was centrifuged at 9,000 rpm for $10 \mathrm{~min}$ to obtain mitochondrial pellets that were then washed twice with cold PBS. The final mitochondrial pellets were re-suspended in the test medium (220 mmol/l Mannitol, $70 \mathrm{mmol} / \mathrm{l}$ Sucrose, $5 \mathrm{mmol} / \mathrm{l}$ HEPES, $\mathrm{pH}$ 7.2) for studies. The final protein concentrations of the mitochondrial suspension were adjusted to $0.3 \mathrm{mg} / \mathrm{ml}$.

Determination of mitochondrial membrane potential. PC-3 cells were cultured in 6 -well plates $(20 \times 20 \mathrm{~mm})$ and then exposed to $0.4 \mathrm{mg} / \mathrm{ml}$ YBT, ABT and TFs for $24 \mathrm{~h}$. The mitochondrial membrane potential $(\Delta \Psi \mathrm{m})$ was estimated using 5,5',6,6'-tetrachloro-1,1',3,3'-tetraethylbenzimidazolecarbocyanide iodide (JC-1, Molecular Probes) (20).

Analysis of cytochrome c release. PC-3 cells were cultured and exposed to $0.4 \mathrm{mg} / \mathrm{ml} \mathrm{YBT,} \mathrm{ABT} \mathrm{and} \mathrm{TFs} \mathrm{for} 24 \mathrm{~h}$, then isolated mitochondria. Contents of the cytochrome $c$ were measured by western blotting (21). The experiments were repeated at least three times.

Assay of cellular ATP contents. The $0.4 \mathrm{mg} / \mathrm{ml} \mathrm{YBT,} \mathrm{ABT}$ and TFs-treated PC-3 cells were washed twice with cold PBS and homogenized with $600 \mu \mathrm{l}$ cold PBS and $80 \mu 10.4 \mu \mathrm{mol} / 1$ perchloric acid by mechanical homogenization at the high speed for $10 \mathrm{~min}$. These samples were adjusted to $\mathrm{pH} 6.0$ with $0.2 \mu \mathrm{mol} / 1 \mathrm{~K}_{2} \mathrm{CO}_{3}$ and centrifuged at $12,000 \mathrm{rpm}$ for $10 \mathrm{~min}$. The supernatant was filtered through the Millipore filter with $0.45-\mu \mathrm{m}$ pore diameter and then injected into HPLC system (LC-2010A, Shimadzu). The samples were analyzed on a $\mathrm{C}_{18}$ column (200x4.6 mm i.d., particle size $\left.5 \mu \mathrm{m}\right)$, where the mobile phase (pH 6.0) was methanol/potassium dihydrogen phosphate/potassium hydrogen phosphate (5: 47.5: 47.5). The flow rate was $1.0 \mathrm{ml} / \mathrm{min}$, the effluent was monitored at $280 \mathrm{~nm}$, and the sample injection volume was $20 \mu \mathrm{l}$. All instruments and the columns were operated at room temperature $\left(23-25^{\circ} \mathrm{C}\right)$. All the experiments were repeated at least three times.

Determination of caspase-3 activity. PC-3 cells were cultured and exposed to $0.4 \mathrm{mg} / \mathrm{ml} \mathrm{YBT,} \mathrm{ABT} \mathrm{and} \mathrm{TFs} \mathrm{for} \mathrm{12,} 24$ and $36 \mathrm{~h}$. The cells were harvested and carried out according to caspase- 3 activity assay kit instructions. The assay was based on spectrophotometric detection of the chromophore $p$-nitroaniline ( $p$ NA) after its cleavage by caspase-3 from the labeled substrate, Ac-DEVD-pNA. Briefly, cell lysates were prepared after their respective treatment. Assays were performed on 96-well plates by incubating $50 \mu \mathrm{l}$ protein of cell lysate per sample in the $50 \mu \mathrm{l}$ reaction buffer containing $5 \mu \mathrm{l}$ caspase-3 substrate (Ac-DEVD- $p$ NA). Lysates were incubated at $37^{\circ} \mathrm{C}$ for $4 \mathrm{~h}$. Samples were measured with an ELISA reader (Thermal Labsystem) at an absorbance of $405 \mathrm{~nm}$.

Statistical analysis. Results were expressed as the means \pm SD of at least three independent replications of each experiment. Statistical significance was determined by pair t-test analysis using Origin 7.5 software for Windows. 

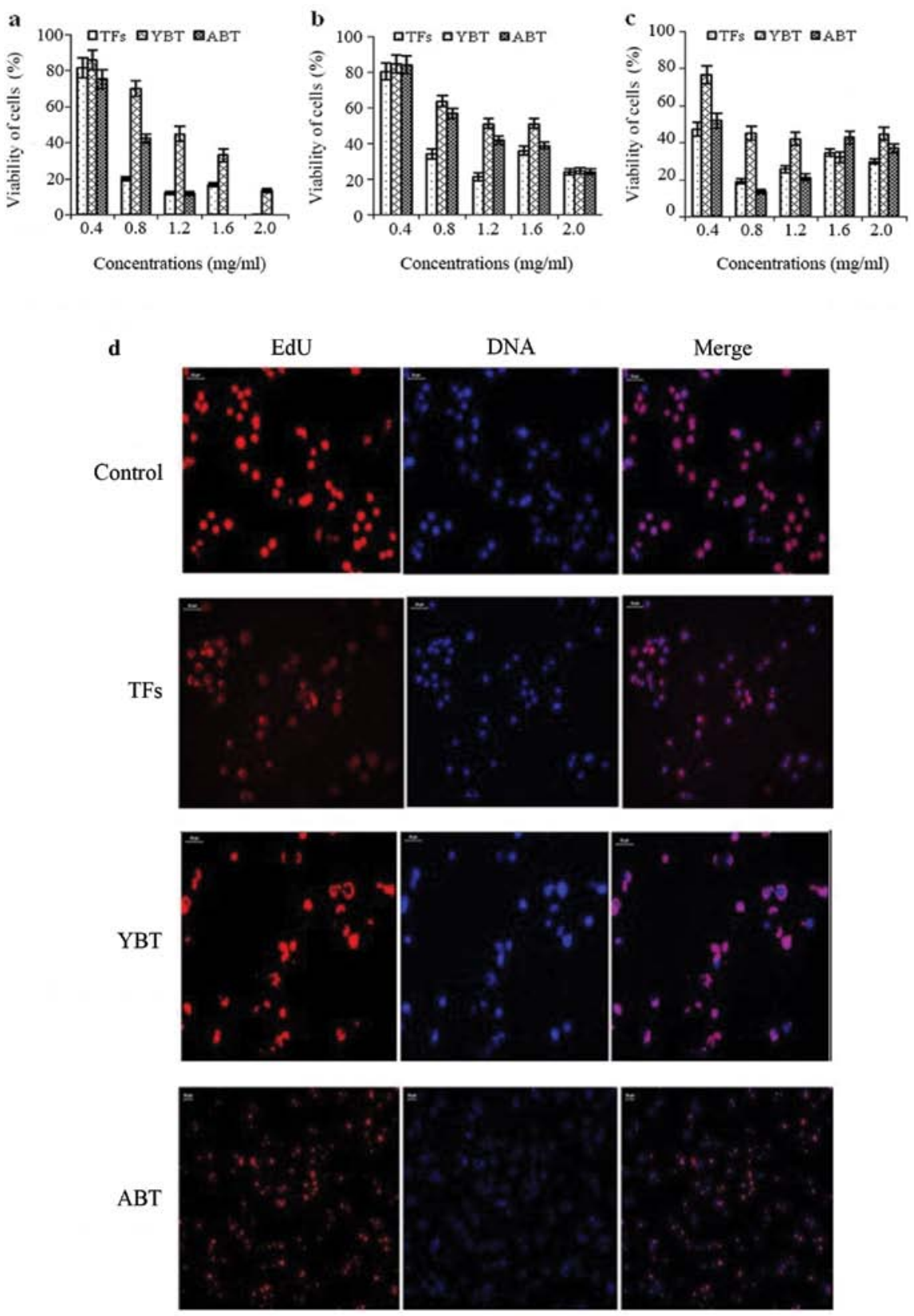

Figure 2. Effects of TFs, YBT and ABT on viability of PC-3 cells. The cells were exposed to TFs, YBT and ABT of different concentrations $(0,0.4,0.8,1.2$, $1.6,2.0 \mathrm{mg} / \mathrm{ml}$ ) for (a) $12 \mathrm{~h}$, (b) $24 \mathrm{~h}$ and (c) $36 \mathrm{~h}$, respectively, and the cell viability was measured by the MTT assay as showed in Materials and methods. The values represent the percent of viable cells, where untreated cells were regarded as $100 \%$ viable. Data are means $\pm \mathrm{SD}$, $\mathrm{n}=7$. (d) Proliferation was estimated using the EdU incorporation assay. Scale bars, $50 \mu \mathrm{m}$. The cells were exposed to TFs, YBT and ABT $(0.4 \mathrm{mg} / \mathrm{ml})$ for $24 \mathrm{~h}$. The proliferation was significantly inhibited.

\section{Results}

Catechin and theaflavin monomers contents. Catechin and theaflavin monomer contents of TFs, YBT and ABT extracts were analyzed by HPLC. As shown in Table I, four kinds of theaflavin monomer contents of TFs were high in comparison with YBT and ABT, respectively. The active ingredients in black tea are theaflavins, thearubigins and theabrownins. The activity of TF3 theaflavin monomer is even more than that of EGCG. TF1, TF2 and TF3 content in three samples is in order of the TFs $>$ ABT $>$ YBT. The theaflavin monomer TF3 content was 193.34, 8.20, $3.23 \mathrm{mg} / \mathrm{g}$ in TFs, ABT and YBT, respectively.
Cell viability of $\mathrm{PC}-3$ cells. The $\mathrm{PC}-3$ cells were exposed to $0.4-2.0 \mathrm{mg} / \mathrm{ml} \mathrm{YBT}$, ABT and TFs for 12, 24 and $36 \mathrm{~h}$, respectively. The MTT assay demonstrated that all the treatment caused suppression of the growth of PC-3 cells. As shown in Fig. 2, after the treatment, the cell viability of PC-3 cells decreased (untreated cells $=100 \%$ ) in a dose-dependent manner and resulted in a maximum loss when the concentration is $2.0 \mathrm{mg} / \mathrm{ml}$. At 12,24 or $36 \mathrm{~h}$, the decrease of the cell viability of PC-3 cells exposed to TFs was more significant than the other two black tea extracts. In addition, the decrease of the cell viability exposed to $A B T$ was more significant than that exposed to YBT. These results suggested that TFs and black tea extracts could significantly inhibit the growth of PC-3 cells. 

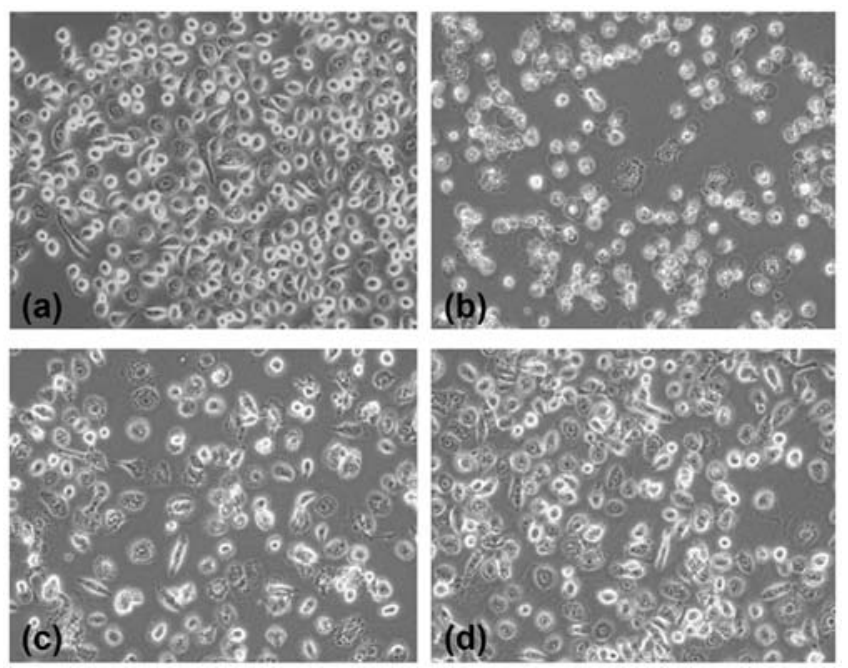

Figure 3. Microscopic images of PC-3 cells treated with TFs, YBT or ABT PC-3 cells were exposed to (a) control, (b) $0.4 \mathrm{mg} / \mathrm{ml} \mathrm{TFs,} \mathrm{(c)} 0.4 \mathrm{mg} / \mathrm{ml} \mathrm{YBT}$, and (d) $0.4 \mathrm{mg} / \mathrm{ml} \mathrm{ABT}$ for $24 \mathrm{~h}$.

Proliferation of PC-3 cells. The proliferation of PC-3 cells was estimated using the EdU incorporation assay. The PC-3 cells $\left(1 \times 10^{5}\right)$ were exposed to $0.4 \mathrm{mg} / \mathrm{ml} \mathrm{YBT,} \mathrm{ABT} \mathrm{and} \mathrm{TFs} \mathrm{for}$ $24 \mathrm{~h}$. EdU incorporation assay showed that YBT, ABT and TFs treatment significantly inhibited PC-3 cell proliferation when compared to that of the control group.

Morphological changes of PC-3 cells. Effects of TFs, YBT and ABT on PC-3 cells were observed through the inverted microscope. The number of PC-3 cells adhering on plate decreased after exposed to $0.4 \mathrm{mg} / \mathrm{ml}$ TFs, YBT and ABT (Fig. 3) respectively, and the number of PC-3 cells adhering on the plates decreased according to the sequence of the control $>$ YBT $>$ ABT $>$ TFs. Moreover, these three treatment made PC-3 cells become round, globular cells and larger than control cells.

Apoptotic and necrotic cells. Apoptosis of the PC-3 cells treated with TFs, YBT or ABT, respectively, was examined using flow cytometry. As shown in Fig. 4, $0.4 \mathrm{mg} / \mathrm{ml} \mathrm{TFs,}$ $0.4 \mathrm{mg} / \mathrm{ml} \mathrm{YBT}$ and $0.4 \mathrm{mg} / \mathrm{ml} \mathrm{ABT}$ induced apoptosis of PC-3 cells, respectively, when compared with that of the control group.

Loss of mitochondrial membrane potential. JC-1 is a fluorescent compound (excitation maximum, $490 \mathrm{~nm}$ ) that exists as a monomer at low concentrations. At higher concentrations, JC-1 forms aggregates. Fluorescence of the monomer is green (emission, $527 \mathrm{~nm}$ ), whereas that of the $\mathrm{J}$ aggregate is red (emission, $590 \mathrm{~nm}$ ). Mitochondria with intact membrane potential $(>100 \mathrm{mV})$ concentrate $\mathrm{JC}-1$ into aggregates that fluoresce red, whereas de-energized mitochondria cannot concentrate $\mathrm{JC}-1$ and fluoresce green. JC-1 staining is widely used to measure mitochondrial membrane potential $(\Delta \Psi \mathrm{m})$. The change from red florescence to green represents the decrease of mitochondrial membrane potential. TFs, YBT and ABT caused a significant loss of mitochondrial membrane potential, as shown in Fig. 5.
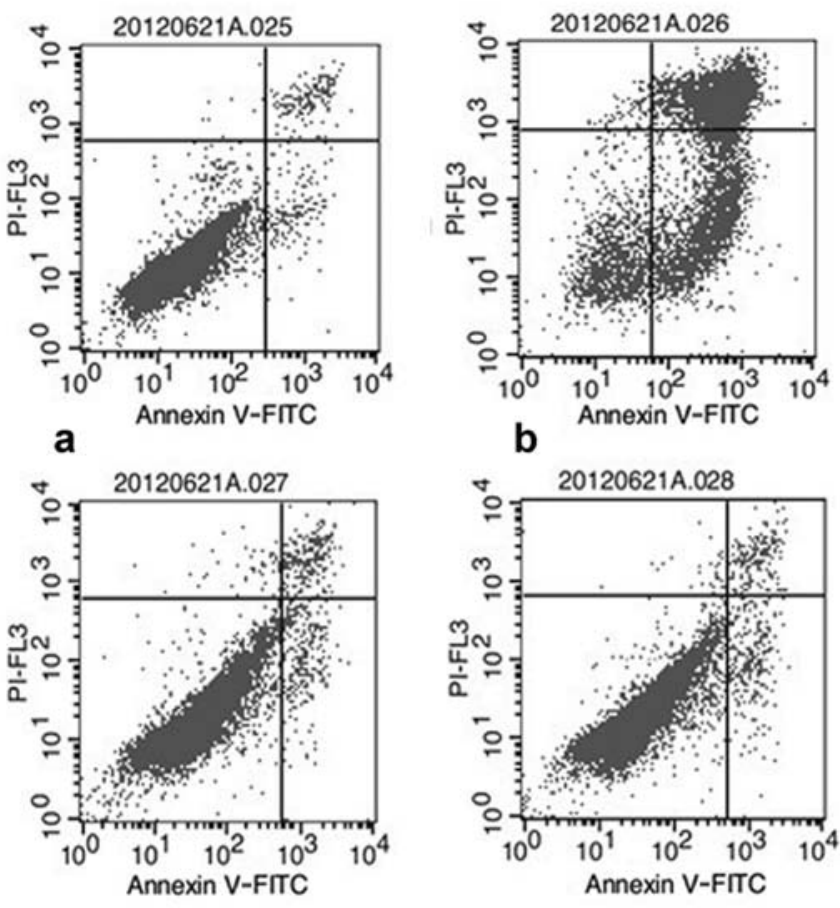

C

d

$\begin{array}{cccccc}\text { Gated } & \text { UL } & \text { UR } & \text { LL } & \text { LR } & \text { UR+LR } \\ \text { Control } & 0.10 \% & 1.54 \% & 96.73 \% & 1.63 \% & 3.17 \% \\ \text { TFs } & 0.66 \% & 56.56 \% & 13.00 \% & 29.78 \% & 86.34 \% \\ \text { YBT } & 0.61 \% & 2.77 \% & 93.54 \% & 3.08 \% & 5.85 \% \\ \text { ABT } & 0.47 \% & 2.12 \% & 93.97 \% & 3.44 \% & 5.56 \%\end{array}$

Figure 4. Apoptosis. PC-3 cells were exposed to (a) control, (b) $0.4 \mathrm{mg} / \mathrm{ml}$ TFs, (c) $0.4 \mathrm{mg} / \mathrm{ml} \mathrm{YBT}$, and (d) $0.4 \mathrm{mg} / \mathrm{ml} \mathrm{ABT} \mathrm{for} 24 \mathrm{~h}$, and analyzed by flow cytometry. TFs, YBT or ABT treatment induced PC-3 cell apoptosis when compared with that of control group.

Concentration of mitochondrial cytochrome $c$. The cytochrome $c$ from the intermembrane space into the cytosol was investigated. Western blot results (Fig. 6) showed that concentrations of the cytochrome $c$ in mitochondria of PC-3 cells treated with TFs, YBT or ABT were all significantly decreased (TFs $>$ YBT $>$ ABT), which suggested that the cytochrome $c$ was released from mitochondria into the cell cytosol.

ATP contents in PC-3 cells. In aerobic organisms, the mitochondria is the main source of energy and site of the tricarboxylic acid (TCA) cycle, a metabolic network is involved in the generation of reducing factors that power the production of ATP (22). In the present study, it was noted that TFs, YBT and ABT inhibited ATP synthesis (Fig. 7), and in particular ATP contents of PC-3 cells treated with TFs was significantly different from the control. The ATP contents in ABT-treated PC-3 cells were lower than that exposed to YBT and higher than that exposed to TFs. These results suggested that TFs, YBT and ABT could induce damage of mitochondria in PC-3 cells.

Effects of caspase-3 activities. Caspase-3 has been shown to play a pivotal role in the execution phase of apoptosis induced by diverse stimuli. In this study, we analyzed its activation in PC-3 cells treated by TFs, YBT or ABT for 12, 24 and $36 \mathrm{~h}$. As shown in Fig. 8, treatment with TFs, YBT and ABT signifi- 

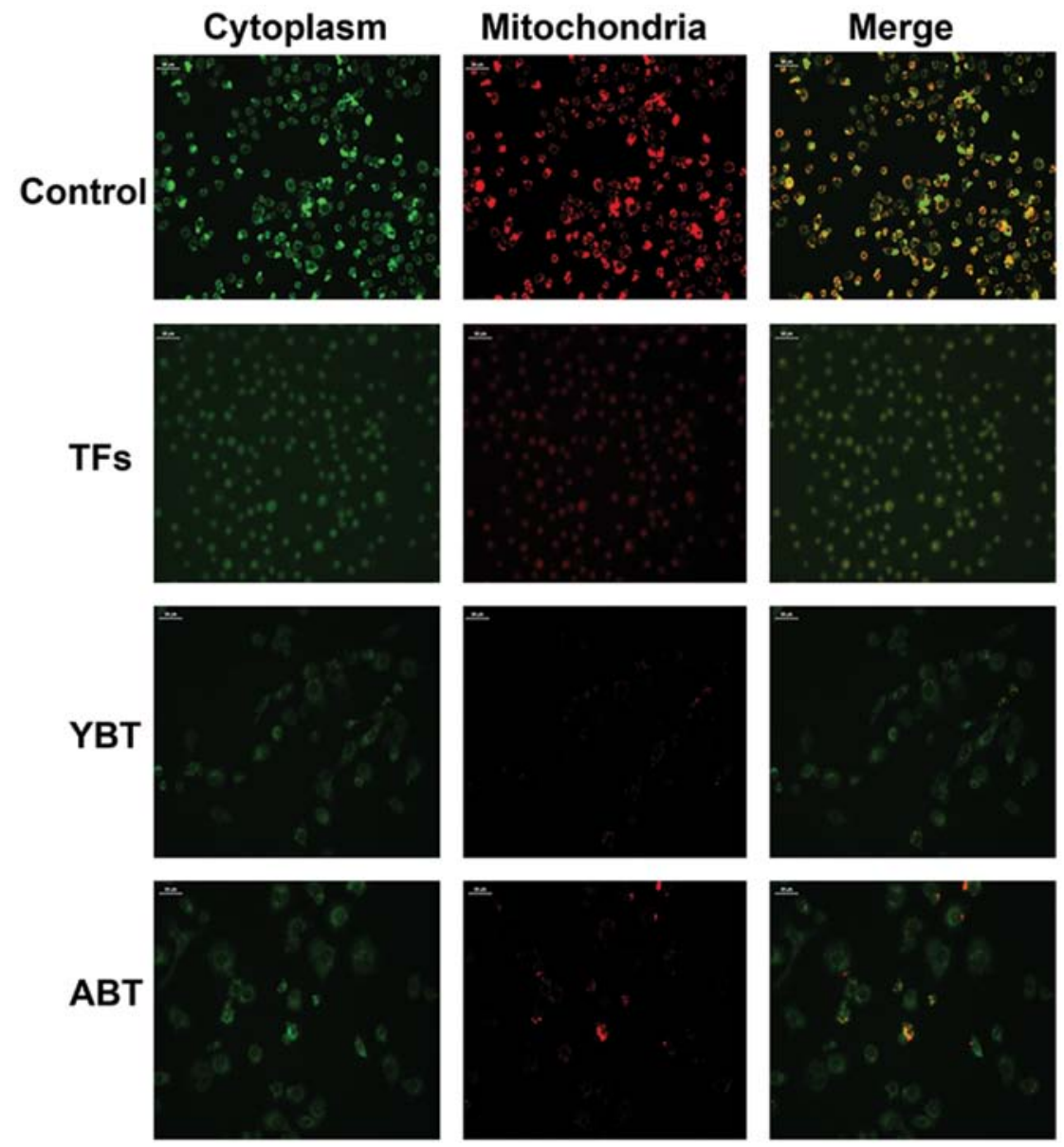

Figure 5. Effects of TFs, YBT and ABT on the mitochondrial membrane potential. PC-3 cells were treated with $0.4 \mathrm{mg} / \mathrm{ml} \mathrm{TFs}, 0.4 \mathrm{mg} / \mathrm{ml} \mathrm{YBT} \mathrm{and} 0.4 \mathrm{mg} / \mathrm{ml}$ ABT for $24 \mathrm{~h}$. The mitochondrial membrane potential was monitored using JC-1 staining. TFs, YBT or ABT treatment decreased mitochondrial membrane potential.

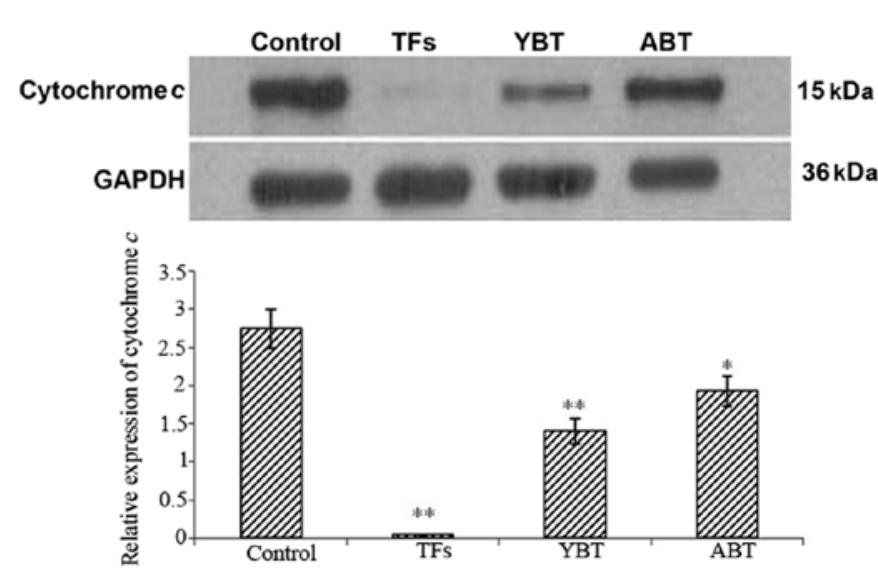

Figure 6. Concentration of cytochrome $c$ in mitochondria of PC-3 cells. PC-3 cells were treated with $0.4 \mathrm{mg} / \mathrm{ml} \mathrm{TFs}, 0.4 \mathrm{mg} / \mathrm{ml} \mathrm{YBT}$ and $0.4 \mathrm{mg} / \mathrm{ml} \mathrm{ABT}$ for $24 \mathrm{~h}$ and then the mitochondria was isolated. Concentration of cytochrome $c$ in PC-3 cells was measured by western blotting. Data are means $\pm \mathrm{SD}, \mathrm{n}=3\left({ }^{*} \mathrm{p}<0.05 ;{ }^{* *} \mathrm{p}<0.01\right)$.

cantly increased activities of caspase-3 in a time-dependent manner, and the effects of treatment were TFs $>$ ABT $>$ YBT. These results indicated that treatment with $0.4 \mathrm{mg} / \mathrm{ml} \mathrm{TFs,}$ YBT or ABT stimulated the caspase-3 activities.

\section{Discussion}

Prostate cancer is one of the leading causes of human male death throughout the world. As estimated, more than 200,000 new cases of prostate cancer are detected in the United States in 2005, and 230,000 men die each year from this disease (23). Prostate cancer is the most common type of cancer except skin cancer, diagnosed in American men (24). However, prostate disease is difficult to cure. The prostate gland has a nonporous capillary bed. In order to traverse the capillary endothelium, an antibiotic must pass through the endothelial cell membranes rather than the pores which are found in capillary beds elsewhere in the body. To reach the prostatic secretions, the drug must traverse the additional lipid barrier of the prostatic epithelium. However, drugs which are poorly lipid-soluble, such as penicillins, cephalosporins and aminoglycosides, traverse the capillary wall very slowly (25).

Our previous studies indicated that EGCG could satisfactorily exhibit complex chemistry with metal ions, and this chelation between EGCG and metal ions changed their bioactivities and metabolisms, which suggested that EGCG could prevent or cure prostate cancer, and $\mathrm{Zn}^{2+}$ and $\mathrm{Cd}^{2+}$ could enhance the inhibitory effect of EGCG against PC-3 cells $(26,27)$. In another study, we demonstrated that $\mathrm{Zn}^{2+}$ enhanced the action of EGCG on PC-3 cells, zinc-EGCG 


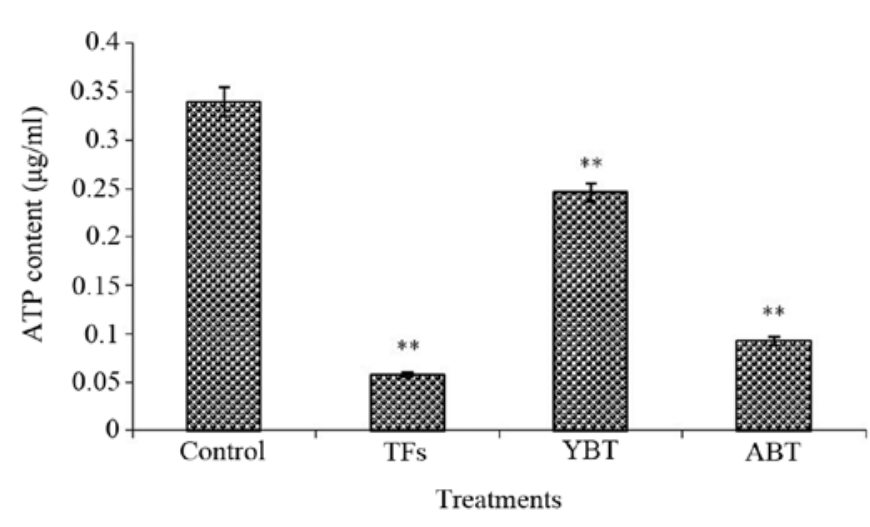

Figure 7. ATP contents of PC-3 cells. PC-3 cells were treated with $0.4 \mathrm{mg} / \mathrm{ml}$ TFs, $0.4 \mathrm{mg} / \mathrm{ml} \mathrm{YBT}$ and $0.4 \mathrm{mg} / \mathrm{ml} \mathrm{ABT}$ for $24 \mathrm{~h}$, and then the mitochondria was isolated. ATP contents of PC-3 cells were measured by HPLC. Data are means $\pm \mathrm{SD}, \mathrm{n}=3\left({ }^{* *} \mathrm{p}<0.01\right)$.

complex was highly unlikely to be formed in the presence of $\mathrm{Zn}^{2+}$ and EGCG and our results also showed the potentiating action of $\mathrm{Zn}^{2+}$ on the growth inhibitory property of EGCG in PC-3 cells (18). In addition, we showed that EGCG induced apoptosis or even necrosis of PC-3 cells through the mitochondria-mediated pathway, and free $\mathrm{Zn}^{2+}$ enhanced effects of EGCG on PC-3 cells due to its interaction with mitochondria (19). However, studies elucidating the mechanisms involved in prostate cancer prevention by black tea are scarce in comparison with green tea. Therefore, in the present study, we report mechanism-based efficacy studies on black tea extracts in PC-3 cells.

Polyphenols present in food have been demonstrated to decrease various types of experimental carcinogenesis $(28,29)$. In recent years, identification of effective chemopreventive polyphenols in diets or dietary supplements for human use is of great interest. Treatment with such polyphenols can result in cell cycle arrest (30), and therefore reduce the growth and proliferation through apoptosis or even necrosis, but only in cancerous, not in normal cells $(31,32)$. In addition, tea polyphenols exert their potent anticancer activity and appear to be the ideal agents for chemoprevention. For the manufacture of black tea, the fermentation process causes green tea polyphenols to oxidise and form oligomeric flavanols, including theaflavins, thearubigin and other oligomers. Theaflavins, a mixture of TF1, TF2A, TF2B and TF3, are the most abundant phenolic fraction of black tea and their structures are not well characterized. Black tea is assumed to be less beneficial compared with green tea. However, studies have demonstrated that black tea could be as effective as green tea in cancer chemoprevention $(10,33,34)$.

Among black tea components, theaflavins are generally considered to be the more effective components for the inhibition of carcinogenesis and account for 3-6\% of dry weight of black tea (35). Black tea has also shown potent inhibition in animal systems, including the lung (36), colon (37) and skin (38). Other studies also provide evidence that black tea can significantly inhibit proliferation and enhance apoptosis in the established mouse skin tumor (39). Black tea polyphenols, especially TFs exert cancer chemopreventive activities by inducing apoptotic signals $(39,40)$. In addition, lots of studies

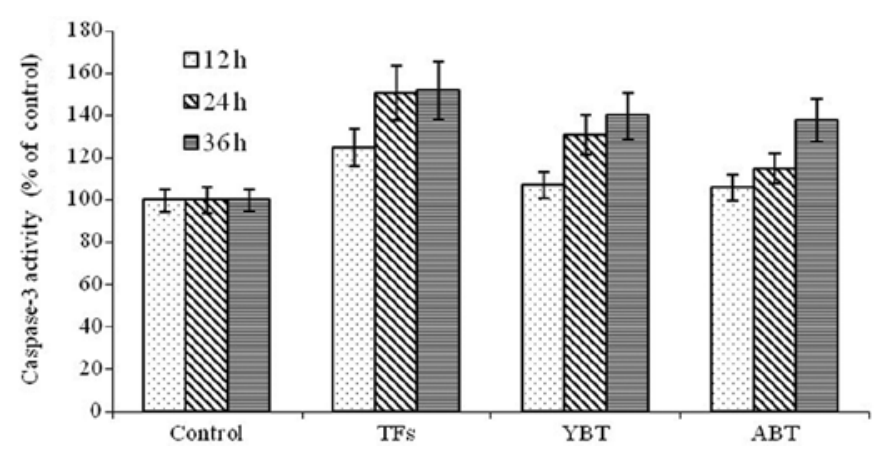

Figure 8. Caspase-3 activities of PC-3 cells treated with TFs, YBT or ABT for 12,24 and $36 \mathrm{~h}$. The cells were harvested and carried out according to caspase-3 activity assay kit instructions. The absorbance was measured in each well at $405 \mathrm{~nm}$ using the ELISA reader as showed in Materials and methods. Data are means $\pm \mathrm{SD}, \mathrm{n}=3$.

have showed that the black tea and its polyphenol theaflavin could induce apoptosis in tumor cells, and such effect was not evident in normal healthy cells (41). This was possibly due to the difference in genetic programming in normal and tumor cells (42).

In the present study, we found that TFs, YBT and ABT all significantly suppressed the viability of PC-3 cells, made PC-3 cells become round, globular cells and bigger than control cells, induced apoptosis of PC-3 cells and even caused necrosis of PC-3 cells. One of the possibilities for why low cell viability at $2 \mathrm{mg} / \mathrm{ml}$ for $12 \mathrm{~h}$ was seen is that at the concentration of $2 \mathrm{mg} / \mathrm{ml}$, the extracts cannot $100 \%$ inhibit cell proliferation and growth, the surviving cell proliferation might contribute to the higher cell viability at 24-36 h. The tea polyphenols or theaflavins in vitro have shown some activities against prostate cancer $(18,19,43)$, and the polyphenol or theaflavin concentrations in our body is much lower than the micromole level $(44,45)$. Therefore, drinking tea can probably prevent the occurrence of prostate cancer, but has almost no effect on curing the patient of prostate cancer.

Similar to green tea polyphenols, black tea and its major polyphenol has antioxidant $(5,46)$ and pro-oxidant dual activities (47). TFs, the characteristic compositions in black tea, are formed via the co-oxidation of pairs of epimerized catechins, one with a vic-trihydroxyphenyl moiety, and the other with an ortho-dihydroxyphenyl structure. Different from epimerized catechins, four main TF derivatives reserve two A-rings, two C-rings from their precursors, and possess a characteristic element of the fused seven-member benzotropolone ring (Fig. 1). It has been suggested that the existence of resonance formed in the benzotropolone moiety might be responsible for electron donation (46). Jhoo et al suggested that the benzotropolone moiety of TFs might play an important role in affording antioxidant protection for the preferred oxidation site in the oxidant models of 2,2-diphenyl-1-picrylhydrazyl and $\mathrm{H}_{2} \mathrm{O}_{2}$ (48). However, theaflavins also exert pro-oxidant behavior (49). Sakagami et al suggested that the antioxidant activity of tea polyphenolics is the driving force to inhibit carcinogenesis, while the pro-oxidant activity accounts for their selective cytotoxicity, growth inhibitory and apoptosis-inducing activity towards tumor cells (50). In addition, Weisburg et al has shown that green tea catechins 
generate ROS in the cell culture medium and increase the intracellular production of ROS (51), which may induce loss of the mitochondrial membrane potential leading to release of apoptotic factors $(52,53)$.

Mitochondria plays an important role in cellular energy metabolism, free radical generation and apoptosis (54). Several mDNA-encoded pro-apoptotic proteins including cytochrome $c$, apoptosis inducing factor (AIF), endonuclease G, and smac/DIABLO normally reside in the mitochondria. Release of these factors from mitochondria triggers a series of biochemical events leading to activation of apoptotic signaling cascades (55).

It is evident from the results of the present study that treatment with TFs, YBT and ABT could induce apoptosis of PC-3 cells through mitochondrial dysfunctioning. This is supported by the observations that exposure of PC-3 cells to TFs, YBT or ABT induced: i) release of cytochrome $c$ from mitochondria and loss of mitochondrial membrane potential that plays a critical role in mitochondria-dependent apoptosis pathway; and ii) a decrease in ATP contents and activation of caspase- 3 that plays a pivotal role in the execution phase of apoptosis induced by diverse stimuli. These results suggest that mitochondrial dysfunction by TFs, YBT and ABT could be responsible for apoptosis of PC-3 cells, and the effects were TFs $>$ extracts of black tea.

In mitochondria, permeability transition pore (PTP) opening causes mitochondrial swelling and loss of the mitochondrial membrane potential. As the matrix expands, the inner membrane keeps the membrane intact, but the outer membrane becomes ruptured. This leads to release of apoptotic factors such as cytochrome $c$, from the intermembrane space into the cytosol. The released cytochrome $c$ complexes with Apaf-1 in the presence of dATP and ultimately cleave procaspase-3 to form active caspase-3. Activation of caspase-3 is an important step in the execution phase of apoptosis and its inhibition blocks cell apoptosis $(56,57)$.

In addition, due to PTP opening, the inner membrane becomes permeable to protons which can lead to uncoupling oxidative phosphorylation. The F1F0-ATPase reverses and hydrolyzes ATP to maintain the mitochondrial membrane potential resulting in a decrease of intracellular ATP concentration. This can lead to the dysfunction of ATP-dependent processes such as disruption of ionic homeostasis, and activation of calcium-dependent degradative enzymes such as phospholipase, nucleases and proteases (58-60). It has been shown that a decrease in intracellular ATP level imposed apoptosis. Along with other evidence in our study, we hypothesized that the decrease of ATP after treatment might contribute to apoptosis (61). In TFs group, changes of ATP contents are proportional to the release of cytochrome $c$ or activity of caspase- 3 . In the YBT and ABT treatment groups, although it seems that the ATP contents are not proportional to the release of cytochrome $c$ or activity of caspase-3, there was no statistical difference.

The human prostate cancer cell lines include androgendependent LNCaP and androgen-independent PC-3 and DU145 cells. Kalra et al (62) reported that black tea polyphenol, theaflavin-induced apoptosis in human prostate carcinoma, LNCaP cells was mediated via modulation of two related pathways: upregulation of $\mathrm{p} 53$ and downregulation of NF- $\mathrm{KB}$ activity, causing a change in the ratio of pro- and anti-apoptotic proteins leading to apoptosis. The altered expression of Bcl-2 family member proteins triggered the release of cytochrome $c$ and activation of initiator capsase- 9 followed by activation of effector caspase-3. Furthermore, TFs also affected the protein expression of mitogen activated protein kinases (MAPK) pathways. Their results demonstrated that TF treatment resulted in downregulation of phospho-extracellular signal-regulated protein kinase (Erk1/2) and phospho-p38 MAPK expressions. Therefore, they concluded that TFs induce apoptosis in LNCaP cells through shifting the balance between pro- and anti-apoptotic proteins and downregulation of cell survival pathways leading to apoptosis. They also showed that TFs induced apoptosis in the androgen-independent prostate cancer cell line PC-3 through caspases and MAPK-mediated pathways. Thus, effect of TFs on prostate cancer cell lines seems to be irrespective of their androgen status (62). Lee et al found that TF3 significantly reduced androgen-responsive LNCaP prostate cancer cell growth, suppressed expression of the androgen receptors and lowered androgen-induced prostate-specific antigen secretion and fatty acid synthase protein level (63). In this study, our findings suggest that black tea and TFs could act as an effective anti-proliferative agent in androgen-independent PC-3 cells.

Recently, Tachibana et al have reported that EGCG inhibited cell growth by inducing the myosin II regulatory light chain (MRLC) phosphorylation (64). It is likely that EGCG could disrupt the contractile ring by decreasing the MRLC phosphorylation resulting in the inhibition of cell proliferation $(65,66)$. In addition, EGCG decreased MRLC phosphorylation by binding to 67LR (a cell surface receptor) (64). Therefore, further studies are needed to identify whether the inhibitory effects of black tea extracts, especially TFs are exerted by their binding to 67LR.

In conclusion, our results suggest that TFs, YBT and ABT could inhibit the growth and change the morphology of prostate cancer cells. Additionally, TFs, YBT and ABT induced apoptosis or even necrosis of PC-3 cells through mitochondrial dysfunctioning.

\section{Acknowledgements}

This study was supported by President Foundation of Guangdong Academy of Agricultural Sciences (no. 201018), Guangdong Provincial Key Laboratory of Tea Plant Resources Innovation and Utilization (no. 2008A060301004), Guangdong Provincial Science and Technology Foundation (no. 2011B031500002 and no. 2012B091100165) and Tea Industry Technology System of China (no. CARS-23).

\section{References}

1. Ankolekar C, Terry T, Johnson K, et al: Anti-hyperglycemia properties of tea (Camellia sinensis) bioactives using in vitro assay models and influence of extraction time. J Med Food 14: 1190-1197, 2011.

2. Elbling L, Herbacek I, Weiss RM, et al: Hydrogen peroxide mediates EGCG-induced antioxidant protection in human keratinocytes. Free Radic Biol Med 49: 1444-1452, 2010.

3. Rains TM, Agarwal S and Maki KC: Antiobesity effects of green tea catechins: a mechanistic review. J Nutr Biochem 22: $1-7,2011$. 
4. Tran PL, Kim SA, Choi HS, Yoon JH and Ahn SG: Epigallocatechin-3-gallate suppresses the expression of HSP70 and HSP90 and exhibits anti-tumor activity in vitro and in vivo. BMC Cancer 10: 276, 2010.

5. Yang Z, Jie G, Dong F, et al: Radical-scavenging abilities and antioxidant properties of theaflavins and their gallate esters in $\mathrm{H}_{2} \mathrm{O}_{2}$-mediated oxidative damage system in the HPF-1 cells. Toxicol In Vitro 22: 1250-1256, 2008.

6. Bushman JL: Green tea and cancer in humans: a review of the literature. Nutr Cancer 31: 151-159, 1998.

7. Roy P, George J, Srivastava S, Tyagi S and Shukla Y: Inhibitory effects of tea polyphenols by targeting cyclooxygenase- 2 through regulation of nuclear factor kappa B, Akt and p53 in rat mammary tumors. Invest New Drugs 29: 225-231, 2011.

8. Uchiyama S, Taniguchi Y, Saka A, Yoshida A and Yajima H: Prevention of diet-induced obesity by dietary black tea polyphenols extract in vitro and in vivo. Nutrition 27: 287-292, 2011.

9. Wan XC: Tea Biochemistry. China Agriculture Press, Beijing, 2003 (In Chinese).

10. Halder $\mathbf{J}$ and Bhaduri AN: Protective role of black tea against oxidative damage of human red blood cells. Biochem Biophys Res Commun 244: 903-907, 1998.

11. Leung LK, Su Y, Chen R, et al: Theaflavins in black tea and catechins in green tea are equally effective antioxidants. J Nutr 131: 2248-2251, 2001.

12. Ye XQ, Li Q, Wang GH, et al: Mitochondrial and energy metabolism-related properties as novel indicators of lung cancer stem cells. Int J Cancer 129: 820-831, 2011.

13. Gomez-Zaera M, Abril J, Gonzalez L, et al: Identification of somatic and germline mitochondrial DNA sequence variants in prostate cancer patients. Mutat Res 595: 42-51, 2006.

14. Salido M, Gonzalez JL and Vilches J: Loss of mitochondrial membrane potential is inhibited by bombesin in etoposideinduced apoptosis in PC-3 prostate carcinoma cells. Mol Cancer Ther 6: 1292-1299, 2007.

15. Qi X, Cai Y, Gong L, et al: Role of mitochondrial permeability transition in human renal tubular epithelial cell death induced by aristolochic acid. Toxicol Appl Pharmacol 222: 105-110, 2007.

16. Saad F and Schulman CC: Role of bisphosphonates in prostate cancer. Eur Urol 45: 26-34, 2004.

17. Taplin ME and Balk SP: Androgen receptor: a key molecule in the progression of prostate cancer to hormone independence. J Cell Biochem 91: 483-490, 2004.

18. Sun SL, He GQ, Yu HN, et al: Free $\mathrm{Zn}^{2+}$ enhances inhibitory effects of EGCG on the growth of PC-3 cells. Mol Nutr Food Res 52: 465-471, 2008

19. Yang J, Yu H, Sun S, et al: Mechanism of free $\mathrm{Zn}^{2+}$ enhancing inhibitory effects of EGCG on the growth of PC-3 cells: interactions with mitochondria. Biol Trace Elem Res 131: 298-310, 2009.

20. Dey R and Moraes CT: Lack of oxidative phosphorylation and low mitochondrial membrane potential decrease susceptibility to apoptosis and do not modulate the protective effect of $\mathrm{Bcl}-\mathrm{x}(\mathrm{L})$ in osteosarcoma cells. J Biol Chem 275: 7087-7094, 2000.

21. Narita M, Shimizu S, Ito T, Chittenden T and Lutz RJ: Bax interacts with the permeability transition pore to induce permeability transition and cytochrome c release in isolated mitochondria. Proc Natl Acad Sci USA 95: 14681-14686, 1998.

22. Lemire J, Mailloux R and Appanna VD: Zinc toxicity alters mitochondrial metabolism and leads to decreased ATP production in hepatocytes. J Appl Toxicol 28: 175-182, 2008.

23. Rebbeck TR: Genetics, disparities, and prostate cancer. LDI Issue Brief 10: 1-4, 2005.

24. Carter HB, Pearson JD, Metter EJ, et al: Longitudinal evaluation of prostate-specific antigen levels in men with and without prostate disease. JAMA 267: 2215-2220, 1992.

25. Barza $M$ and Cuchural G: The penetration of antibiotics into the prostate in chronic bacterial prostatitis. Eur J Clin Microbiol 3: 503-505, 1984

26. Chen X, Yu H, Shen S and Yin J: Role of $\mathrm{Zn}^{2+}$ in epigallocatechin gallate affecting the growth of PC-3 cells. J Trace Elem Med Bio 21: $125-131,2007$

27. Zhang LC, Yu HN, Sun SL, et al: Investigations of the cytotoxicity of epigallocatechin-3-gallate against PC-3 cells in the presence of $\mathrm{Cd}^{2+}$ in vitro. Toxicol In Vitro 22: 953-960, 2008.

28. Kuroda Y and Hara Y: Antimutagenic and anticarcinogenic activity of tea polyphenols. Mutat Res 436: 69-97, 1999.
29. Araújo JR, Goncalves P and Martel F: Chemopreventive effect of dietary polyphenols in colorectal cancer cell lines. Nutr Res 31: 77-87, 2011 .

30. Lepley DM, Li B, Birt DF and Pelling JC: The chemopreventive flavonoid apigenin induces $\mathrm{G} 2 / \mathrm{M}$ arrest in keratinocytes. Carcinogenesis 17: 2367-2375, 1996.

31. Hall PA, Coates PJ, Ansari B and Hopwood D: Regulation of cell number in the mammalian gastrointestinal tract: the importance of apoptosis. J Cell Sci 107: 3569-3577, 1994.

32. Wiseman S, Mulder T and Rietveld A: Tea flavonoids: bioavailability in vivo and effects on cell signaling pathways in vitro. Antioxid Redox Signal 3: 1009-1021, 2001.

33. Weisburger JH, Rivenson A, Garr K and Aliaga C: Tea, or tea and milk, inhibit mammary gland and colon carcinogenesis in rats. Cancer Lett 114: 323-327, 1997.

34. Liang YC, Chen YC, Lin YL, et al: Suppression of extracellular signals and cell proliferation by the black tea polyphenol, theaflavin-3,3'-digallate. Carcinogenesis 20: 733-736, 1999.

35. Stoner GD and Mukhtar H: Polyphenols as cancer chemopreventive agents. J Cell Biochem 22: 169-180, 1995.

36. Yang GY,Liu Z, Seril DN, et al: Black tea constituents, theaflavins, inhibit 4-(methylnitrosamino)-1-(3-pyridyl)-1-butanone (NNK)induced lung tumorigenesis in $\mathrm{A} / \mathrm{J}$ mice. Carcinogenesis 18: 2361-2365, 1997.

37. Weisburger JH, Rivenson A, Reinhardt J, et al: Effect of black tea on azoxymethane-induced colon cancer. Carcinogenesis 19: 229-232, 1998

38. Javed S, Mehrotra NK and Shukla Y: Chemopreventive effects of black tea polyphenols in mouse skin model of carcinogenesis. Biomed Environ Sci 11: 307-313, 1998.

39. Lu YP, Lou YR, Xie JG, et al: Inhibitory effect of black tea on the growth of established skin tumors in mice: effects on tumor size, apoptosis, mitosis and bromodeoxyuridine incorporation into DNA. Carcinogenesis 18: 2163-2169, 1997.

40. Yang GY, Liao J, Li C, et al: Effect of black and green tea polyphenols on c-jun phosphorylation and $\mathrm{H}_{2} \mathrm{O}_{2}$ production in transformed and non-transformed human bronchial cell lines: possible mechanisms of cell growth inhibition and apoptosis induction. Carcinogenesis 21: 2035-2039, 2000.

41. Lu J, Ho CT, Ghai G and Chen KY: Differential effects of theaflavin monogallates on cell growth, apoptosis, and Cox-2 gene expression in cancerous versus normal cells. Cancer Res 60: 6465-6471, 2000.

42. Kundu T, Dey S, Roy M, Siddiqi M and Bhattacharya RK: Induction of apoptosis in human leukemia cells by black tea and its polyphenol theaflavin. Cancer Lett 230: 111-121, 2005.

43. Prasad S, Kaur J, Roy P, Kalra N and Shukla Y: Theaflavins induce $\mathrm{G} 2 / \mathrm{M}$ arrest by modulating expression of $\mathrm{p} 21 \mathrm{waf} 1 / \mathrm{cip} 1$, cdc25C and cyclin B in human prostate carcinoma PC-3 cells. Life Sci 81: 1323-1331, 2007.

44. Rietveld A and Wiseman S: Antioxidant effects of tea: evidence from human clinical trials. J Nutr 133: S3285-S3292, 2003.

45. Henning SM, Aronson W, Niu Y, et al: Tea polyphenols and theaflavins are present in prostate tissue of humans and mice after green and black tea consumption. J Nutr 136: 1839-1843, 2003.

46. Wu YY, Li W, Xu Y, Jin EH and Tu YY: Evaluation of the antioxidant effects of four main theaflavin derivatives through chemiluminescence and DNA damage analyses. J Zhejiang Univ Sci B 12: 744-751, 2011

47. Babich H, Gottesman RT, Liebling EJ and Schuck AG: Theaflavin-3-gallate and theaflavin-3'-gallate, polyphenols in black tea with prooxidant properties. Basic Clin Pharmacol Toxicol 103: 66-74, 2008.

48. Jhoo JW, Lo CY, Li S, et al: Stability of black tea polyphenol, theaflavin, and identification of theanaphthoquinone as its major radical reaction product. J Agric Food Chem 53: 6146-6150, 2005.

49. Babich H, Pinsky SM, Muskin ET and Zuckerbraun HL: In vitro cytotoxicity of a theaflavin mixture from black tea to malignant, immortalized, and normal cells from the human oral cavity. Toxicol In Vitro 20: 677-688, 2005.

50. Sakagami T, Satoh K, Ishihara M, et al: Effect of cobalt ion on radical intensity and cytotoxic activity of antioxidants. Anticancer Res 20: 3143-3150, 2000.

51. Weisburg JH, Weissman DB, Sedaghat T and Babich H: In vitro cytotoxicity of epigallocatechin gallate and tea extracts to cancerous and normal cells from the human oral cavity. Basic Clin Pharmacol Toxicol 95: 191-200, 2004. 
52. Zamzami N, Marchetti P, Castedo M, et al: Sequential reduction of mitochondrial transmembrane potential and generation of reactive oxygen species in early programmed cell death. J Exp Med 182: 367-377, 1995.

53. Zamzami N, Marchetti $\mathrm{P}$, Castedo $\mathrm{M}$, et al: Reduction in mitochondrial potential constitutes an early irreversible step of programmed lymphocyte death in vivo. J Exp Med 181: $1661-1672,1995$

54. Carew JS and Huang P: Mitochondrial defects in cancer. Mol Cancer 1: 9, 2002.

55. Wang X: The expanding role of mitochondria in apoptosis. Genes Dev 15: 2922-2933, 2001

56. Budihardjo I, Oliver H,Lutter M, Luo X and Wang X: Biochemical pathways of caspase activation during apoptosis. Annu Rev Cell Dev Biol 15: 269-290, 1999.

57. Thornberry NA and Lazebnik Y: Caspases: enemies within Science 281: 1312-1316, 1998.

58. Armstrong JS: The role of the mitochondrial permeability transition in cell death. Mitochondrion 6: 225-234, 2006.

59. Tsujimoto Y, Nakagawa T and Shimizu S: Mitochondrial membrane permeability transition and cell death. Biochim Biophys Acta 1757: 1297-1300, 2006.

60. Jung JY, Mo HC, Yang KH, et al: Inhibition by epigallocatechin gallate of $\mathrm{CoCl} 2$-induced apoptosis in rat $\mathrm{PCl}_{2}$ cells. Life Sci 80: 1355-1363, 2007.
61. Behera MA, Dai QS, Garde R, et al: Progesterone stimulates mitochondrial activity with subsequent inhibition of apoptosis in MCF-10A benign breast epithelial cells. AM J Physiol Endocrinol Metab 297: E1089-E1096, 2009.

62. Kalra N, Seth K, Prasad S, et al: Theaflavins induced apoptosis of $\mathrm{LNCaP}$ cells is mediated through induction of p53, downregulation of NF-kappa B and mitogen-activated protein kinases pathways. Life Sci 80: 2137-2146, 2007.

63. Lee HH, Ho CT and Lin JK: Theaflavin-3,3'-digallate and penta-O-galloyl-beta-D-glucose inhibit rat liver microsomal 5alpha-reductase activity and the expression of androgen receptor in $\mathrm{LNCaP}$ prostate cancer cells. Carcinogenesis 25: $1109-1118,2004$

64. Tachibana H, Koga K, Fujimura Y and Yamada K: A receptor for green tea polyphenol EGCG. Nat Struct Mol Biol 11: 380-381, 2004.

65. Umeda D, Tachibana H and Yamada K: Epigallocatechin-3-Ogallate disrupts stress fibers and the contractile ring by reducing myosin regulatory light chain phosphorylation mediated through the target molecule $67 \mathrm{kDa}$ laminin receptor. Biochem Biophys Res Commun 333: 628-635, 2005.

66. Fujimura Y, Umeda D, Kiyohara Y and Sunada Y: The involvement of the $67 \mathrm{kDa}$ laminin receptor-mediated modulation of cytoskeleton in the degranulation inhibition induced by epigallocatechin-3-O-gallate. Biochem Biophys Res Commun 348: 524-531, 2006. 